\title{
En conmemoración de los 85 años del Prof. Dr. Georg Eisenhauer
}

\author{
In remembrance of $85^{\text {th }}$ birthday of Prof. Dr. Georg Eisenhauer
}

JUAN E. SCHLATTER V.

Universidad Austral de Chile, Facultad Ciencias Forestales, Casilla 567, Valdivia. E-mail: jschlatt@uach.cl

El profesor Dr. Georg Eisenhauer fue Jefe del Proyecto "Convenio Interuniversitario entre las Facultades de Ingeniería Forestal de la Universidad de Göttingen, Alemania, y la Universidad Austral de Chile en Valdivia, Chile". El convenio aludido, vigente entre los años 1966 y 1973, aportó en ese período con nueve profesores y docentes alemanes; seis de los cuales se desempeñaron en forma simultánea y permanente en la carrera de Ingeniería Forestal, lo que permitió dotar a la entonces Facultad de Ingeniería Forestal de la Universidad Austral de Chile, en Valdivia, con académicos chilenos especializados en el extranjero y personal administrativo adecuado para permitir su consolidación definitiva y proyectarse como una de las Escuelas de Ingeniería Forestal más prestigiosas de Latinoamérica. Además, equipó a la Facultad en Chile con los instrumentos y vehículos necesarios para su operación y también se lograron establecer las bases para el trabajo conjunto entre ambas Universidades, de Chile y Alemania.

El profesor Eisenhauer nació el 16 de mayo de 1920 en la zona del Odenwald, Alemania; debió combatir en la segunda guerra mundial y sólo después se formó como Ingeniero Forestal en las Universidades de Göttingen y Freiburg, graduándose en 1949. Después de su graduación cumple labores relacionadas con su profesión en el Estado de Hessen hasta 1952 y durante este período contrae matrimonio en el año 1950 con Ursula, quien será su compañera de vida y con quien tendrá cuatro hijos.

En 1952 se integra al Instituto de Trabajo y Maquinaria Forestal de la Universidad de Göttingen. En 1957 obtiene el grado de Doctor en Ciencias Forestales de la Universidad de Göttingen y es incorporado al Ministerio de Agricultura y Bosques del Estado de Hessen hasta el año 1959. En ese año toma a su cargo una unidad de administración forestal (superficie de bosques repartida en varias propiedades rurales), principalmente de bosques estatales y comunitarios, y es nombrado, a su vez, Director de la Escuela Forestal de Rhoden, en la que se capacitan operarios forestales.

En junio de 1965 inicia su participación en el proyecto de un convenio interuniversitario entre las Facultades de Ingeniería Forestal de la Universidad de Göttingen, Alemania, y la Universidad Austral de Chile, en Valdivia, Chile; es parte del grupo que apoya el proyecto y luego lo dirigirá desde agosto de 1966 hasta inicios de 1973. Aquí asume como jefe de proyecto y, al mismo tiempo, es Director del Instituto de Utilización de Bosques de la Facultad en Valdivia. El proyecto es financiado y sustentado por la Sociedad Alemana para la Cooperación Técnica, del Ministerio para la Ayuda al Desarrollo de Alemania, y consultó una inversión extraordinaria de la Universidad Austral de Chile, con apoyo estatal, para consolidar la Facultad de Ingeniería Forestal. Esta Facultad se fundó en 1954 en la Universidad como respuesta a la necesidad de la región de contar con un centro para la formación de ingenieros forestales y para el desarrollo de estudios sobre los bosques y su entorno, para establecer las bases de su manejo, en una época en que Valdivia fue la ciudad con el mayor desarrollo de 
la industria elaboradora de la madera del país, pero en que los bosques nativos ya mostraban claros signos de agotamiento en sus reservas de madera de calidad.

El convenio consideró fortalecer especialmente las materias de suelos, silvicultura, sanidad forestal, utilización forestal, economía forestal, política forestal, tecnología de la madera, manejo forestal y elaboración industrial de la madera. También incluyó el requerimiento a la contraparte de Chile para establecer una unidad de manejo o área de bosques de propiedad de la Universidad, que sirviera para la docencia y la investigación forestal y por este intermedio posibilitar en ella el desarrollo libre de la creación, sin presiones contingentes, y para una formación de los ingenieros forestales fortalecida en forma importante por prácticas en terreno. El énfasis inicial en silvicultura, en la organización profesional, fue modificado durante el convenio por una formación integral de los ingenieros forestales, que debían ser generalistas y con fuertes fundamentos en suelos y ecología, silvicultura y protección del bosque, economía y manejo, sistemas de cosecha y tecnología de la madera y su industrialización.

El sector forestal del país era dirigido en esa época por industriales, generalmente autodidactas, o por ingenieros agrónomos del sector público, hasta el inicio de la década de 1970, desde la cual fue fortaleciéndose la administración forestal del Estado con ingenieros forestales, quienes fueron incorporados paulatinamente también a la empresa privada. Esto demandó que la gestión del convenio Göttingen-Valdivia estuviera a cargo de una persona que tuviera la adecuada diplomacia y capacidad negociadora, para llevar a concreción el proyecto, lo que se demostró en la persona del Prof. Georg Eisenhauer.

Al terminar el convenio indicado anteriormente en 1973, y por el notable éxito de su gestión, el Profesor Eisenhauer fue distinguido como Profesor Honorario por la Universidad Austral de Chile. A su vez, la Universidad de Göttingen lo nombra Profesor Honorario de esa Universidad, en 1974.

Al volver a Alemania asumió por un año un cargo administrativo superior en la Administración Regional de Darmstadt, y luego como Director del Instituto de Ciencia del Trabajo del Centro Federal de Investigaciones Forestales y Madereras en Reinbeck, en las cercanías de Hamburgo, entre 1974 y 1985, siendo también presidente del Centro Federal de Investigaciones Forestales y Madereras de Hamburgo entre 1978 y 1981.

Durante sus funciones como Director del Instituto dicta clases en las Universidades de Hamburgo y Göttingen en cosecha forestal y transporte de maderas, como también utilización de bosques tropicales y subtropicales, respectivamente. También cumple misiones en países extranjeros, como Bolivia, Brasil, Chile, de Centroamérica, Ecuador, México, Paraguay, Perú, Arabia Saudita, China y Sudán.

Una vez concluidas sus funciones en Reinbeck, es enviado nuevamente al extranjero, ahora a la República Argentina, donde asume en 1985 como Jefe de un Proyecto de la Sociedad Alemana para la Cooperación Técnica, para el Asesoramiento al Instituto Forestal Nacional (IFONA), con sede en Buenos Aires, Argentina. Este proyecto debió atender aspectos de política forestal, organización institucional del sector forestal, educación, investigación y extensión forestal. De aquí resultaron numerosos documentos sobre legislación forestal y organización institucional del sector y se fundaron tres instituciones: el Centro de Investigación y Extensión Forestal Andino-Patagónico (CIEFAP), en Esquel, Chubut; la Escuela de Técnicos Forestales Las Marías en Virasoro, Corrientes, y el Centro de Tecnología de la Madera en Montecarlo, Misiones. También se elaboró gran cantidad de material audiovisual para la información pública sobre el sector forestal y su potencial en la República Argentina. Este trabajo lo finaliza el año 1991, asumiendo un merecido descanso por su jubilación. Aun así siguió asesorando a empresas alemanas que tenían proyectos de 
inversión en el noreste de Argentina, contactos que aún mantiene hoy para asuntos puntuales.

Todos los que hemos tenido el honor de haberlo conocido y los que tuvieron la posibilidad de haber sido favorecidos por la obra que él dirigió, nos hacemos un grato deber de rendir un público reconocimiento a quien entregara toda su creatividad y esfuerzo para el desarrollo del sector forestal académico y no académico en el sur de Chile.

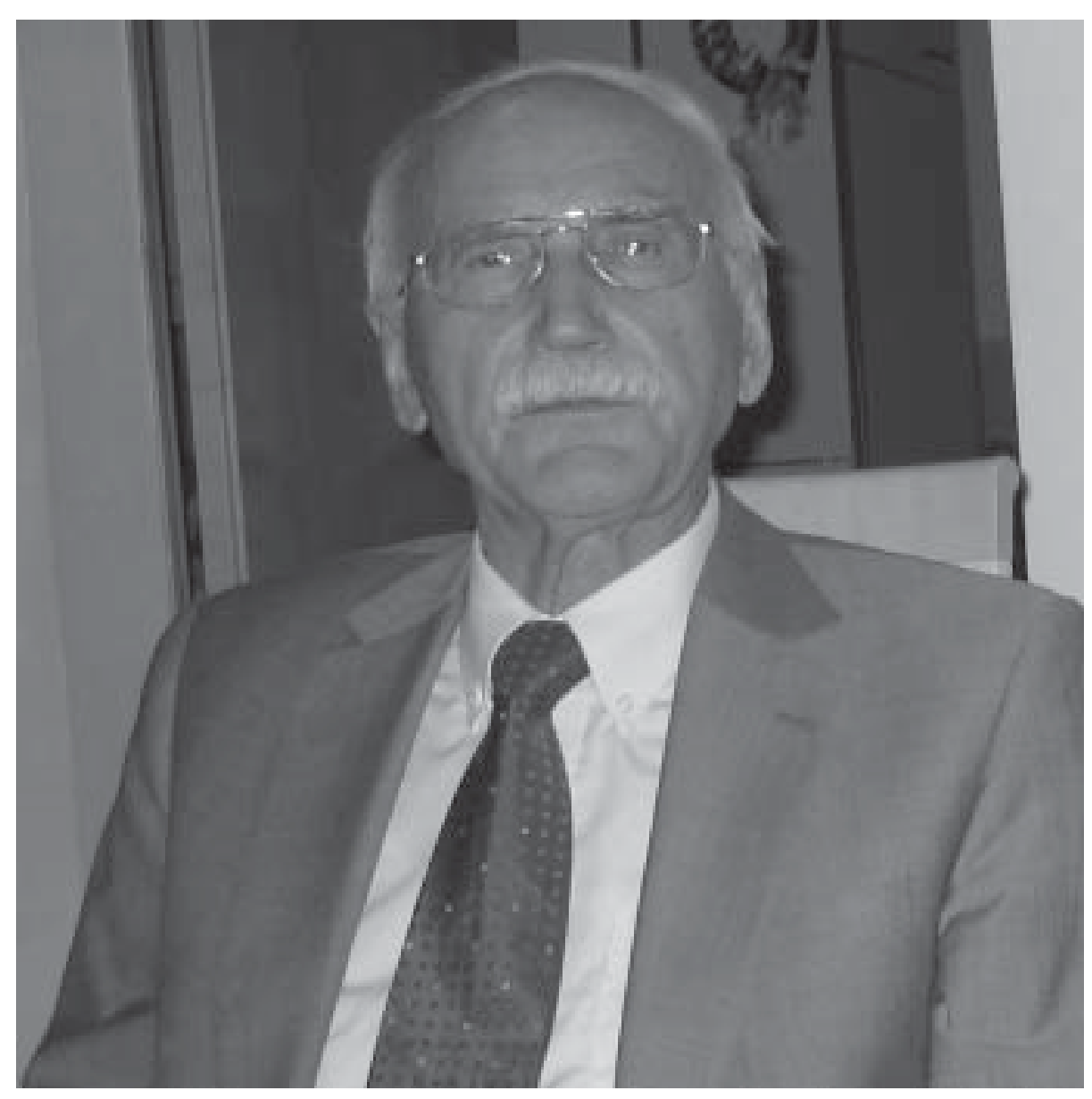

Prof. Dr. Georg Eisenhauer 